\title{
Hand Unit of Length
}

National Cancer Institute

\section{Source}

National Cancer Institute. Hand Unit of Length. NCI Thesaurus. Code C71216.

A traditional unit of length equal to 4 inches or 10.16 centimeters. 